\title{
nature
}

\section{International panel for GM food?}

A proposal to set up a body analogous to the Intergovernmental Panel on Climate Change has much to commend it. But it raises questions that should critically influence the allocation of responsibility.

$\mathrm{t}$ would have been unrealistic to expect any dramatic conclusions from last week's three-day meeting on the safety of genetically modified (GM) foodstuffs, hosted by the UK government and run jointly with the Organisation for Economic Co-operation and Development (OECD; see page 112). Conceived at the height of vocal demands last year for a global moratorium on the commercial planting of GM foods, its main function was to help lower the temperature of a debate that was rapidly leading to a trade war. In this it appears to have succeeded. But many of the gaps between those keen to promote such technologies and their critics remain as wide as ever.

Any attempt to establish a permanent forum in which the dialogue can continue, as proposed at the end of the meeting, could be ineffectual for those reasons. Broad differences in philosophy remain - for example, between those convinced that GM crops hold the key to meeting the food requirements of the Third World, and others who say they are unnecessary because the problem is primarily one of food distribution. Such differences will not be resolved by a discussion whose starting point is the science behind safety issues. They require a broader agenda and more mutual trust between participants — or at least more common ground over the facts and practicalities.

Nor should one be seduced by the simplistic argument that what worked for climate change will also work for GM crops. The Intergovernmental Panel on Climate Change was able to organize much of its work around a single question - whether there is a man-made component of current global warming - to which many scientists already felt they had, if not the answer, then a great deal to contribute. 'Is GM food safe?' is a very different type of question, requiring elements of judgement that cannot be resolved through data and simulations alone.

More positively, an international panel could present political decision-makers with conclusions shorn of the more excessive claims of either the proponents or critics of GM foods. Thus, it could play a useful role in identifying the key issues at stake, for example on the implications for human health or environmental safety.

Achieving this does not require starting from the science, even though scientific judgements as to which claims are more plausible than others would be a major component in such a panel's deliberations, and could help establish important new scientific agendas to sustain public confidence. An equally important component would be the trust in the process held by stakeholders in the debate. Here, openness, transparency and a commitment to priority consideration of the interests not only of commerce but also of consumers worldwide are crucial. So is the willingness to acknowledge the legitimacy of a wide range of views, not just to listen to them politely. Any organization keen to take on responsibility for such a panel would do well to commit itself publicly to such requirements.

In offering itself as a candidate, the OECD has a lot to prove. The proceedings of an important conference held in 1997 on the controversial regulatory issue of substantial equivalence have only recently been de-restricted, not least because of the time it took to satisfy participating governments about the report's contents. That sort of track record, and a historical lack of time for anti-GM lobbyists, does not, on the face of it, bode well for the OECD's suitability to take responsibility for the stewardship of this highly charged debate.

\section{Re-reforming Unesco}

The organization's director-general should focus more closely on core goals.

$\mathrm{H}$ istory suggests that Koïchiro Matsuura, director-general of the United Nations Educational, Scientific and Cultural Organization (Unesco) since late last year, has a few years in which to improve it before he risks being taken in by its own propaganda and becomes as inward-looking as his most recent predecessors. A forthright speech last week (see page 113) shows that he means well. Only time will tell whether he can change the culture so radically that he avoids the self-aggrandizing traps that snared Amadou-Mahtar M'Bow and, less disastrously but still notably, Federico Mayor.

Following the fiefdom that Unesco became in the '70s and '80s under M'Bow, which led to the exit of the United States, Singapore and the United Kingdom, Mayor achieved significant reforms, restoring sufficient confidence to encourage the United Kingdom to rejoin. But latterly he lost that touch. Last year's World Conference on Science was widely seen as having failed to make the most of a significant opportunity to place science at the centre of the international political and economic stage.

The success of Matsuura - a Japanese lawyer, diplomat and deputy foreign minister - will depend on whether he is able to entice the United States back into the organization. This will at least need a prompt but fair examination of the questionable 'eleventh-hour' appointments Mayor sprang on Unesco just before leaving. Commendably, Matsuura is forthright in highlighting the difficulties he faces, and is rightly focusing first on management.

But a sharpening of Unesco's programmes is essential. Some have suggested that it should take a lead in the International Year for the Culture of Peace. A look at Unesco's declaration on its Culture of Peace programme is not encouraging - a plethora of worthy motions spanning the sale of small arms and the rights of women. Like most of the motions carried at the World Conference on Science, these have little to offer by way of leverage and, therefore, seem likely to do little for the future reputation of Unesco or for world peace.

At the heart of Unesco's mandate is a commitment to education, with science and culture inextricably linked with it. Science education is not the answer to many short-term problems in society's handling of science-related issues, but its improvement is an urgent need nevertheless, in both developed and developing countries. Some prompt, tangible new achievements to that end, within existing programmes and also embedded as goals in its next medium-term strategy, could do Unesco a lot of good. 